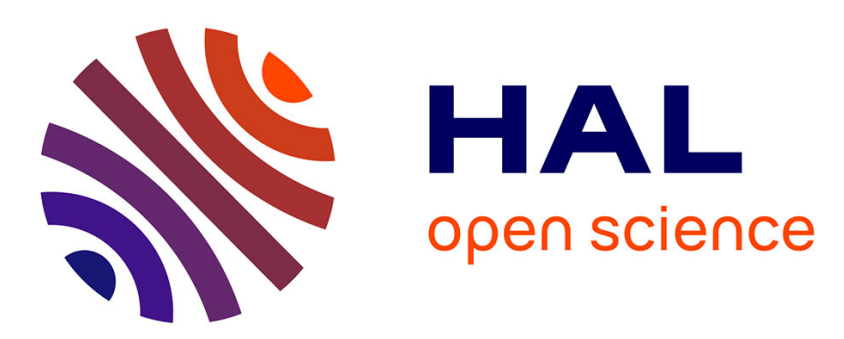

\title{
Assessing the Impact of Anger State on the Three Attentional Networks With the ANT-I
}

Franck Techer, Christophe Jallais, Alexandra Fort, Yves Corson

\section{To cite this version:}

Franck Techer, Christophe Jallais, Alexandra Fort, Yves Corson. Assessing the Impact of Anger State on the Three Attentional Networks With the ANT-I. Emotion, 2015, 15 (3), pp. 276-280. 10.1037/emo0000028. hal-01228425v2

\section{HAL Id: hal-01228425 \\ https://hal.science/hal-01228425v2}

Submitted on 1 Jun 2016

HAL is a multi-disciplinary open access archive for the deposit and dissemination of scientific research documents, whether they are published or not. The documents may come from teaching and research institutions in France or abroad, or from public or private research centers.
L'archive ouverte pluridisciplinaire HAL, est destinée au dépôt et à la diffusion de documents scientifiques de niveau recherche, publiés ou non, émanant des établissements d'enseignement et de recherche français ou étrangers, des laboratoires publics ou privés. 


\title{
BRIEF REPORT
}

\section{Assessing the Impact of Anger State on the Three Attentional Networks With the ANT-I}

\author{
Franck Techer \\ French Institute of Science and Technology for Transport, \\ Development and Networks, Bron, France, and \\ University of Nantes
}

\author{
Christophe Jallais and Alexandra Fort \\ French Institute of Science and Technology for Transport, \\ Development and Networks, Bron, France
}

\author{
Yves Corson \\ University of Nantes
}

\begin{abstract}
Anger is a negative and highly aroused emotion. Previous research has revealed that a high level of arousal can induce the participant in a physical preparation and self-awareness. The aim of this research was to study the influence of anger on the attentional network using the Attention Network TestInteractions (ANT-I). This test has been developed in order to assess 3 attentional networks: alerting, orienting, and executive control. Here, participants were induced in anger using the autobiographic recall procedure or in a neutral mood before the realization of the ANT-I. As expected, the results showed a better alerting score for the angry group. The possible origin of this alerting gain related to the high level of arousal is discussed. The results obtained should enlighten the interaction between emotion and the functioning of the attentional system. They also may be relevant for applied fields related to anger.
\end{abstract}

Keywords: attention network test, anger state, phasic alertness, auditory signal, alerting

This article may not exactly replicate the final version published in the APA journal. It is not the copy of record.

Most studies about emotion and attention compared emotional with neutral stimuli processing to underline a bias of attention. It has been shown that stimuli inducing a high level of arousal have been related to difficulties in the disengagement of attention (e.g., Fox, Russo, Bowles, \& Dutton, 2001). In particular, anger, which is characterized by a negative valence and a high arousal, can provoke an attentional focusing toward its source (Harmon-Jones, Gable, \& Price, 2013). In order to better understand the effect of anger on attention, it could also be useful to study these effects on the processing of neutral stimuli.

According to Posner and Petersen (1990) attention is composed of three independent networks: alerting, orienting, and

Franck Techer, TS2-LESCOT, French Institute of Science and Technology for Transport, Development and Networks, Bron, France, and LPPL, Laboratoire de Psychologie des Pays de la Loire, University of Nantes; Christophe Jallais and Alexandra Fort, TS2-LESCOT, French Institute of Science and Technology for Transport, Development and Networks; Yves Corson, LPPL, Laboratoire de Psychologie des Pays de la Loire, University of Nantes.

We thank the anonymous reviewers for the time they have spent in discussing our work. Their insightful comments and suggestions helped us to improve the quality of the article. The authors would also like to thank Pr. J. Lupiànez for the E-prime version of the ANT-I.

Correspondence concerning this article should be addressed to Techer Franck, IFSTTAR, Cité des Mobilités, 25 Avenue François Mitterrand, 69675 Bron Cedex, France. E-mail: franck.techer@ifsttar.fr executive control. Fan, McCandliss, Sommer, Raz, and Posner (2002) designed the Attention Network Test (ANT), a single task assessing the efficiency of each attentional network at the same time. The ANT is the combination of a cueing task (e.g., Posner, Snyder, \& Davidson, 1980) and a flankers task (Eriksen \& Eriksen, 1974). Although the ANT was a reliable test, Callejas, Lupiàñez, Funes, and Tudela (2005) pointed out that both alerting and orienting scores were obtained from the same cue conditions, leading to a confused interaction between these networks. Thus, they developed the Attention Network TestInteractions (ANT-I) to assess these two networks independently. They also made the orienting cue nonpredictive in order to assess exogenous rather than endogenous attention measured in the ANT.

The ANT and the ANT-I have already been used to assess the impact of emotional states on attention. In their study about the anxiety-state, Pacheco-Unguetti, Acosta, Callejas, and Lupiáñez (2010) observed that the alerting and orienting networks were positively impacted, whereas the anxiety-trait altered the executive control network. Moreover, Pêcher, Quaireau, Lemercier, and Cellier (2011) showed that sadness could affect the orienting function. To our knowledge, anger has not been studied using these tests.

This article aims to assess the impact of anger-state on neutral stimuli processing using the ANT-I. Knowing that anger is linked to a high level of arousal and that arousal can improve the sensitivity to the environment by implying a cognitive and physiological excitation (see Thayer, 1989), we expected an increased effi- 
ciency of the alerting network. We did not expect any effect of anger on the orienting and the executive control networks.

\section{Method}

\section{Participants}

Forty-one volunteers ( 23 to 44 years; $M=31, S D=6$ ) took part in this experiment. Twenty were induced in anger using an auto-

AQ: 4 biographical recall procedure (anger group, 13 females) and 21 in a neutral mood (control group, 15 females). Participants were AQ: 5 randomly assigned to one of the two groups. The research protocol was approved by the ethic committee of the French Institute of Science and Technology for Transport, Development and Networks.

\section{Mood Induction}

Participants were induced either in an angry or a neutral mood. In order to induce anger, the autobiographical recall procedure was used (see Jallais \& Gilet, 2010). Participants had to recall and write down an angry event they experienced. They were encouraged to provide as

AQ: 6 many details as they could. They were given $10 \mathrm{~min}$ to perform this task. In the control group, participants were asked to listen to a 10-min music (Teyssaire, 2003) session (see Jallais \& Gilet, 2010).

To evaluate the arousal dimension, the Affect Grid (Russell, Weiss, \& Mendelsohn, 1989) adapted by Eich and Metcalfe (1989) was used. Participants were given a matrix made of 81 squares ( 9 lines $\times 9$ columns). The horizontal and vertical axes represented the valence and the arousal, respectively. Participants had to mark one square according to their current mood. The valence dimension was assessed using a modified version of the Brief Mood Introspection Scale (BMIS; Mayer \& Gaschke, 1988), developed by Corson and Verrier (2007), to estimate anger state in a more precise way than with the Affect Grid. This version consists in a list of 16-item self-report questionnaire in which each adjective is rated on a 7-point scale.

\section{ANT-I}

Apparatus and stimuli. Stimuli were presented on a 17-in. computer screen using OpenSesame (Mathôt, Schreij, \& Theeuwes, 2012). Responses were collected using an external numeric pad, and participants received auditory stimuli through headphones. We used the ANT-I paradigm, previously developed by Callejas et al. (2005).

Design. A fixation cross $\left(0.44^{\circ}\right.$ angular size $)$ was presented at the center of the screen during the whole session. After a $400 \mathrm{~ms}$ to $1600 \mathrm{~ms}$ random time, an auditory alert $(2,000 \mathrm{~Hz})$ was presented for half of the trials during $50 \mathrm{~ms}$ (tone vs. no-tone conditions). Then, after $400 \mathrm{~ms}$, in two thirds of the trials, an orienting cue (a $0.32^{\circ}$ asterisk) was presented for $100 \mathrm{~ms}$ at $1.03^{\circ}$ above or below the fixation point. Finally, after $100 \mathrm{~ms}$, a line of arrows appeared. The target central arrow was flanked by four arrows (two on each side). Each arrow was $0.55^{\circ}$ long and they were

AQ: 7 separated by $0.06^{\circ}$ of visual angle from each other. The four flanking arrows could either (a) point in the same direction as the central arrow (i.e., congruent trials), (b) point in the opposite direction of the central arrow (i.e., incongruent trials), or (c) be replaced entirely with horizontal lines (i.e., neutral trials). The target could be displayed at the same location as the orienting cue for one third of the trials (cued-location condition) or at the opposite location for one third of the trials (uncued-location condition). In the other trials, no orienting cue was presented (no-cue condition). The target arrow was displayed until the participant response, or for a maximum of 1,700 $\mathrm{ms}$. The fixation point was AQ: 8 displayed until the trial reached $4,150 \mathrm{~ms}$ so that it was not possible for the participants to anticipate the beginning of every new trial.

The 18 possible conditions of 2 auditory alert (tone; no tone) $\times$ 3 orienting cue (cued-location; no-cue; uncued-location) $\times 3$ congruency (congruent; incongruent; neutral) were presented randomly, each condition being repeated 8 times, giving a total of 144 trials.

Task and procedure. Participants had to indicate as fast and as accurately as possible the direction in which the central arrow pointed using the keypad (" 4 " for left and " 6 " for right).

Participants were seated at $53 \mathrm{~cm}$ from the computer screen. They were told to keep their eyes on the fixation point for the whole test. They completed a 20-trials training session, then filled out the first BMIS and Affect Grid to assess their mood state (Moment 1). Afterward, they followed the Mood Induction Procedure (MIP) according to their mood groups and completed a second mood assessment before the experimental task (Moment 2).

\section{Results}

Scores of valence and arousal were presented in Table 1.

\section{Valence Assessment}

A repeated measures ANOVA on the 2 (mood) $\times 2$ (moment) interaction was carried out with mood as an intersubject factor, moment as a within-subject factor, and mean rating for anger adjectives (BMIS) as a dependent factor. Analysis revealed a main AQ: 10 effect of mood, $F(1,39)=14.93, M S E=0.77, p<.0001$, and a main effect of the moment, $F(1,39)=34.61, M S E=0.10, p<$ .0001 . Analysis also revealed a significant Mood $\times$ Moment interaction, $F(1,39)=52.33, M S E=0.10, p<.0001$. Within groups, planned comparisons showed that the anger-group mean ratings for adjectives denoting anger increased between the first and the second mood check, $F(1,39)=83.98, M S E=0.10, p<$ .0001 . No significant effect was found for the control-group planned comparison between the first and the second mood check, $F(1,39)=0.93, M S E=0.10, p=.34$. Between-groups comparisons revealed no difference between the anger and the control

Table 1

Mean (SD) Valence and Arousal Ratings for Both Mood Groups, According to the Moment

\begin{tabular}{lrr}
\hline & Moment 1 & Moment 2 \\
\hline Valence & & \\
Anger & $1.34(2.43)$ & $2.26(0.99)$ \\
Control & $1.10(1.14)$ & $1.00(0.82)$ \\
Arousal & & \\
$\quad$ Anger & $1.4(0.44)$ & $1.7(1.42)$ \\
Control & $1.05(1.94)$ & $-0.33(1.88)$ \\
\hline
\end{tabular}


groups for the first anger rating, $F(1,39)=1.45, M S E=0.42, p=$ .23. But a significant difference between the two groups for the second mood check was found, $F(1,39)=35.26, M S E=0.46$, $p<.0001$. Note that three outliers were present in the anger group at Moment 1, which could reduce the effects on the attentional networks. Their potential influences were checked, but similar results were observed, and then these outliers were kept in the analysis.

\section{Arousal Assessment}

A repeated measures ANOVA on the 2 (mood) $\times 2$ (moment) interaction was carried out with mood as intersubject factor, moment as within subject factor, and the Affect Grid mean ratings for arousal as dependent variable. Analysis revealed a main effect of mood, $F(1,39)=6.05, M S E=4.82, p<.05$, and a main effect of moment, $F(1,39)=10.34, M S E=0.58, p<.01$. Analysis also revealed a significant interaction between mood and moment, $F(1$, $39)=25.00, M S E=0.58, p<.0001$. Within-groups planned comparisons showed that anger-group mean ratings for arousal dimension of the Affect Grid did not differ between the first and the second mood check, $F(1,39)=1.55, M S E=0.58, p=.22$. The planned comparison between the two moments showed that control-group mean ratings for arousal dimension of the affect significantly decreased, $F(1,39)=20.02, M S E=0.58, p<.0001$. Between-groups comparisons revealed no difference between the anger and the control group for the first arousal rating, $F(1,39)=$ $0.49, M S E=2.61, p=.49$, but a significant difference between the two groups in the second mood check, $F(1,39)=15.17$, $M S E=2.79, p<.001$. Thus, the anger group was in a higher aroused state than the control group after the MIP.

\section{ANT-I}

As expected, neutral trials did not differ from congruent trials, $F<1$, so we decided to exclude them from the analysis (Callejas et al., 2005).

Response time (RT) analysis. A 2 (mood) $\times 2$ (auditory alert) $\times 3$ (orienting cue) $\times 2$ (congruency) repeated measures ANOVA was carried out with mood (anger/control) as a betweensubjects factor, and auditory alert (tone/no tone), orienting cue (cued-location/uncued-location/no-cue), and congruency (congruent/incongruent) as within-subject factors. RTs faster or slower than two standard deviations from the mean per participant were filtered out and represented less than $3 \%$ of the trials.

The main effects of auditory alert, $F(1,39)=12.49, M S E=$ $3672, p<.01$, orienting cue, $F(2,39)=95.19, M S E=2587, p<$ .0001 , and congruency factors, $F(1,39)=417.27, M S E=4335$, $p<.001$, were statistically significant, with RTs being faster in the tone than in the no-tone condition, and in the congruent than in the incongruent condition. Planned comparisons showed that RTs were faster in the cued-location than in the no-cue condition, $F(1$, $39)=111.01, M S E=3125.8, p<.0001$, and the uncued-location condition, $F(1,39)=142.96, M S E=2732.1 p<.0001$. We did not observe any statistical differences concerning the no-cue and uncued-location conditions, $F(1,39)=0.68, M S E=1903.77, p=$ .41. No significant main effect of mood was found (see Table 2).

The usual interactions between auditory alert and orienting cue, $F(2,78)=10.49, M S E=1487, p<.0001$, and between orienting
Table 2

Mean Correct Reaction Times in Milliseconds (SD) Obtained for the Two Groups as a Function of Auditory Signal, Orienting Cue, and Congruency

\begin{tabular}{llllll}
\hline & \multicolumn{2}{c}{ Anger } & & \multicolumn{2}{c}{ Control } \\
\cline { 2 - 3 } \cline { 6 - 6 } \cline { 5 - 6 } & Tone & No tone & & Tone & No tone \\
\hline Cued location & & & & \\
$\quad$ Congruent & $473(49)$ & $505(74)$ & & $490(113)$ & $496(111)$ \\
$\quad$ Incongruent & $575(67)$ & $608(89)$ & & $589(123)$ & $600(118)$ \\
No cue & & & & & \\
$\quad$ Congruent & $524(45)$ & $562(67)$ & & $535(148)$ & $571(137)$ \\
$\quad$ Incongruent & $642(86)$ & $713(115)$ & & $651(134)$ & $659(119)$ \\
Uncued location & & & & & \\
$\quad$ Congruent & $549(53)$ & $542(59)$ & & $539(116)$ & $527(98)$ \\
Incongruent & $683(63)$ & $698(95)$ & $675(137)$ & $675(137)$ \\
\hline
\end{tabular}

cue and congruency, $F(2,78)=9.40, M S E=1920, p<.001$, were also observed. No significant interaction was found, however, between auditory alert and congruency, $F(1,39)=1.59$, $M S E=1155, p=.21$

Importantly, the analysis also revealed the predicted interaction between auditory alert and mood, $F(1,39)=4.09, M S E=3672$, $p<.05$.

Complementary analysis. Afterward, three one-way ANOVAs were carried out to test the effect of mood on the attentional networks scores. The three attentional scores were calculated following the ANT-I method (see Callejas et al., 2005; Figure 1). The F1 alerting network score was calculated by subtracting the tone from the no-tone conditions, only considering the no-cue condition. The orienting network score was calculated by subtracting the cuedlocation from the uncued-location conditions. The executive control network score was calculated by subtracting the congruent from the incongruent conditions.

These analyses revealed an effect of mood on the alerting score, AQ: 11 $F(1,39)=4.27, M S E=10622.3, p<.05$. No significant effect of mood was found concerning the orienting score, $F(1,39)=2.22$,

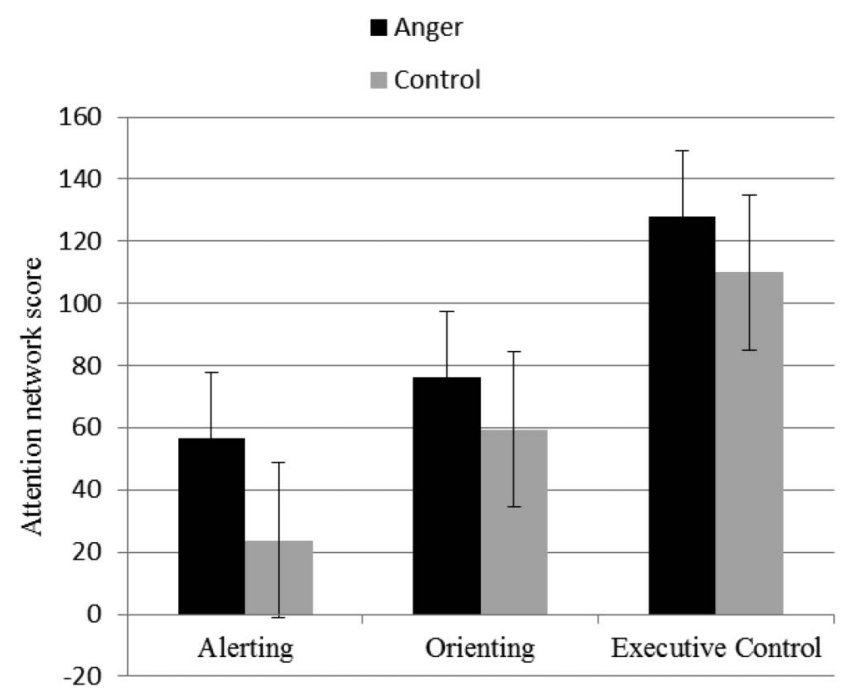

Figure 1. Attentional scores according to mood groups. 
$M S E=3028.5, p=.14$, and the executive control score, $F(1,39)=$ $1.03, M S E=1484.7, p=.32$.

We wondered if the larger alerting effects observed here were particularly associated with the arousal and/or the anger level. On one hand, correlations between the arousal ratings and the three attentional scores were calculated, but none were significant. On the other hand, the correlation between phasic alertness and anger valence ratings $(r=.43, p<.05)$, and between the orienting and anger valence ratings $(r=.47, p<.05)$, were significant. Those correlations suggest that the effects observed are specific to anger and not to a general state of arousal. Moreover, we wondered whether this larger effect could arise from a lack of vigilance for the control group rather than a real alertness increase for the anger group (lower arousal after a potentially boring or wearisome experimental session). The planned comparison between both groups for no-tone/no-cue trials was not significant, $F(1,39)=$ $0.45, M S E=10234.19, p>.05$, suggesting that participants were in a comparable state of vigilance.

\section{Discussion}

In this research, participants were induced so as to study the influence of anger on the three attentional networks: alerting, orienting, and executive control. As expected, the MIP was efficient in the induction of the valence dimension. Although the MIP did not lead to increased perceived arousal for the anger group, the two groups (control and anger) differed significantly in the arousal ratings at the second evaluation.

As expected, analysis showed that angry participants were faster than the control group when an auditory alert was present, revealing a greater alerting effect. However, no significant effect of anger was observed for the orienting or the executive control network. The increase of alerting effect observed here seems to be induced specifically by anger rather than arousal. This may explain the difference compared with the results obtained by Huertas, Zahonero, Sanabria, and Lupiañez (2011) for arousal induced by physical exercise.

One possible explanation for the effect of anger on the alerting network could be physiological. Indeed, it is interesting that the locus cœruleus, which is thought to be involved in the alerting network with the right frontal and parietal regions (Fan et al., 2002; Posner \& Rothbart, 2007), is one of the noradrenergic systems. Marrocco and Davidson (1998) revealed that the noradrenaline modulates the efficiency of the alerting network. Moreover, the noradrenergic systems modulate the arousal state (Berridge, 2008). In addition, anger could cause stronger noradrenergic responses (Ax, 1953; Stemmler, Aue, \& Wacker, 2007). Therefore, the stronger alerting effect for angry participants may be explained by a higher level of noradrenaline.

However, in this study, results did not reveal any increased efficiency for the orienting or the executive control networks. The activity of the former, associated with parietal and frontal areas, could be modulated by acetylcholine (Davidson \& Marrocco, 2000; Fan et al., 2002). In addition, the activity of the latter is modulated by dopamine levels in frontal-subcortical areas (Hosen-

AQ: 12 bocus \& Chahal, 2012). Therefore, the differences between the physiological and anatomical bases in the three attentional networks (Fan et al., 2009) could explain why we had difficulty observing similar effects of anger on the two other attentional networks (orientation and executive control).

This experiment only took into account the effect of anger-state, but the literature has showed differences between anger-trait and anger-state. For instance, the results obtained by Stephens and Groeger (2009) revealed that a high trait-anger could lead to consider low anger-evoking events as highly anger-evoking events. Further studies could deal with the induction of high trait-anger participants to an anger state so as to maximize the efficiency of the arousal induction and to reinforce the impact of the MIP. High anger-trait participants could take more advantage of the auditory alert, and even more when they are experiencing anger.

Although the standard ANT-I tasks incorporate at least 288 trials, only 144 trials were run in this experiment to fit the duration of the MIP efficiency. Even if it could be difficult to compare the size of the attentional indexes with those reported elsewhere, it is nonetheless true that the effects observed on the RTs from the control group are consistent with those already observed in the literature (Callejas et al., 2005; Pacheco-Unguetti et al., 2010). These results suggest that the ANT-I is suitable to assess the attention during short periods like induced moods duration using a low number of trials.

Finally, understanding the effect of anger on attention could be useful in applied domains like driving. Indeed, it is known that experiencing anger while driving can cause a lack of attention for stimuli located away from the expected location of hazards (Stephens, Trawley, Madigan, \& Groeger, 2013). However, Weinbach \& Henik (2011) have showed that alertness could broaden the scope of the attentional focus. Thus, it could be interesting to know whether angry drivers could take better advantage of the driving assistance systems that rely on auditory alerts. Studies about anger and attentional mechanisms could be very relevant in improving road safety and in designing driving assistance systems.

\section{References}

Ax, A. F. (1953). The physiological differentiation between fear and anger in humans. Psychosomatic Medicine, 15, 433-442. doi:10.1097/00006842195309000-00007

Berridge, C. W. (2008). Noradrenergic modulation of arousal. Brain Research Reviews, 58, 1-17. doi:10.1016/j.brainresrev.2007.10.013

Callejas, A., Lupiàñez, J., Funes, M. J., \& Tudela, P. (2005). Modulations among the alerting, orienting and executive control networks. Experimental Brain Research, 167, 27-37. doi:10.1007/s00221-005-2365-z

Corson, Y., \& Verrier, N. (2007). Emotions and false memories valence or arousal? Psychological Science, 18, 208-211. doi:10.1111/j.1467-9280 2007.01874.x

Davidson, M. C., \& Marrocco, R. T. (2000). Local infusion of scopolamine into intraparietal cortex slows covert orienting in rhesus monkeys. Jour nal of Neurophysiology, 83, 1536-1549.

Eich, E., \& Metcalfe, J. (1989). Mood dependent memory for internal versus external events. Journal of Experimental Psychology: Learning, Memory, and Cognition, 15, 443-455. doi:10.1037/0278-7393.15.3.443

Eriksen, B. A., \& Eriksen, C. W. (1974). Effects of noise letters upon the identification of a target letter in a nonsearch task. Perception \& Psychophysics, 16, 143-149. doi:10.3758/BF03203267

Fan, J., Gu, X., Guise, K. G., Liu, X., Fossella, J., Wang, H., \& Posner, M. I. (2009). Testing the behavioral interaction and integration of attentional networks. Brain and Cognition, 70, 209-220. doi:10.1016/j bandc.2009.02.002 
Fan, J., McCandliss, B. D., Sommer, T., Raz, A., \& Posner, M. I. (2002). Testing the efficiency and independence of attentional networks. Journal of Cognitive Neuroscience, 14, 340-347. doi:10.1162/089892902317361886

Fox, E., Russo, R., Bowles, R., \& Dutton, K. (2001). Do threatening stimuli draw or hold visual attention in subclinical anxiety? Journal of Experimental Psychology: General, 130, 681-700. doi:10.1037/00963445.130.4.681

Harmon-Jones, E., Gable, P. A., \& Price, T. F. (2013). Does negative affect always narrow and positive affect always broaden the mind? Considering the influence of motivational intensity on cognitive scope. Current Directions in Psychological Science, 22, 301-307. doi:10.1177/ 0963721413481353

Hosenbocus, S., \& Chahal, R. (2012). A review of executive function deficits and pharmacological management in children and adolescents. Journal of the Canadian Academy of Child and Adolescent Psychiatry, 21, 223-229.

Huertas, F., Zahonero, J., Sanabria, D., \& Lupiañez, J. (2011). Effects of aerobic exercise on the attentional networks. Journal of Sport \& Exercise Psychology, 33, 649-665.

Jallais, C., \& Gilet, A.-L. (2010). Inducing changes in arousal and valence: Comparison of two mood induction procedures. Behavior Research Methods, 42, 318-325. doi:10.3758/BRM.42.1.318

AQ: 15 Marrocco, R. T., \& Davidson, M. C. (1998). Neurochemistry of attention. In R. Parasuraman (Ed.), The attentive brain (p. 35-50). Cambridge, MA: MIT Press.

Mathôt, S., Schreij, D., \& Theeuwes, J. (2012). OpenSesame: An opensource, graphical experiment builder for the social sciences. Behavior Research Methods, 44, 314-324. doi:10.3758/s13428-011-0168-7

Mayer, J. D., \& Gaschke, Y. N. (1988). The experience and metaexperience of mood. Journal of Personality and Social Psychology, 55, 102-111. doi:10.1037/0022-3514.55.1.102

Pacheco-Unguetti, A. P., Acosta, A., Callejas, A., \& Lupiáñez, J. (2010). Attention and anxiety different attentional functioning under state and trait anxiety. Psychological Science, 21, 298-304. doi:10.1177/ 0956797609359624

Pêcher, C., Quaireau, C., Lemercier, C., \& Cellier, J.-M. (2011). The effects of inattention on selective attention: How sadness and rumina- tions alter attention functions evaluated with the Attention Network Test. European Review of Applied Psychology, 61, 43-50. doi:10.1016/j.erap .2010.10.003

Posner, M. I., \& Petersen, S. E. (1990). The attention system of the human brain. Annual Review of Neuroscience, 13, 25-42. doi:10.1146/annurev .ne.13.030190.000325

Posner, M. I., \& Rothbart, M. K. (2007). Research on attention networks as a model for the integration of psychological science. Annual Review of Psychology, 58, 1-23. doi:10.1146/annurev.psych.58.110405.085516

Posner, M. I., Snyder, C. R., \& Davidson, B. J. (1980). Attention and the detection of signals. Journal of Experimental Psychology, 109, 160174. doi:10.1037/0096-3445.109.2.160

Russell, J. A., Weiss, A., \& Mendelsohn, G. A. (1989). Affect Grid: A single-item scale of pleasure and arousal. Journal of Personality and Social Psychology, 57, 493-502. doi:10.1037/0022-3514.57.3.493

Stemmler, G., Aue, T., \& Wacker, J. (2007). Anger and fear: Separable effects of emotion and motivational direction on somatovisceral responses. International Journal of Psychophysiology, 66, 141-153. doi: 10.1016/j.ijpsycho.2007.03.019

Stephens, A. N., \& Groeger, J. A. (2009). Situational specificity of trait influences on drivers' evaluations and driving behaviour. Transportation Research Part F: Traffic Psychology and Behaviour, 12, 29-39.

Stephens, A. N., Trawley, S. L., Madigan, R., \& Groeger, J. A. (2013). Drivers display anger-congruent attention to potential traffic hazards. Applied Cognitive Psychology, 27, 178-189. doi:10.1002/acp.2894

Teyssaire, J. P. (2003). Obscure clarté, éveil des fleurs et brume [Dark AQ: 16 brightness, awakening of flowers and mist] [CD]. Origins: Honey-B Publishing.

Thayer, R. (1989). The biopsychology of mood and arousal. New York, NY: Oxford University Press.

Weinbach, N., \& Henik, A. (2011). Phasic alertness can modulate executive control by enhancing global processing of visual stimuli. Cognition, 121, 454-458. doi:10.1016/j.cognition.2011.08.010

Received April 30, 2014

Revision received August 29, 2014

Accepted September 2, 2014 